\title{
LA DISCUSIÓN SOBRE EL CARÁCTER DEÓNTICO DE LAS NORMAS DE COMPETENCIA: OBLIGACIÓN O PERMISO
}

\author{
Carla HUERTA O.
}

\section{Resumen:}

El objeto del artículo es analizar el carácter deóntico de las normas de competencia, más que definir el concepto de competencia. En este caso, la competencia es entendida como un poder conferido por el sistema jurídico a ciertas autoridades, como la capacidad de crear, modificar o extinguir relaciones jurídicas o posiciones. Sólo un par de tesis son examinadas, a fin de evaluar si esas normas tienen un carácter deóntico autónomo o presentan una combinación de características independientes. La relevancia de las respuestas está relacionada con cuestiones acerca de la responsabilidad, la coerción y las consecuencias jurídicas.

\section{Palabras clave:}

Sistema jurídico, competencia, poderes jurídicos, carácter deóntico, normas, permisión, obligación.

\section{Abstract:}

The aim of this article is to analyze the deontic character of norms of competence, more than to define a concept of competence. Competence is here 
CARLA HUERTA O.

understood as a power given by the legal system to a certain authority, as the capacity to create, modify or extinguish legal relations or positions. Only a couple of theses are examined to evaluate whether these norms have an autonomous deontic character, a complex modality or present a combination of independent characters. The relevance of the answers is related to questions about responsibility, coercion and legal consequences.

\section{Keywords:}

Legal System, Competence, Legal Powers, Deontic Character, Norms, Permission, Obligation. 
Sumario: I. Delimitación del objeto. II. Posturas doctrinales. III. Sobre el carácter deóntico de las normas de competencia. IV. Conclusiones.

\section{Delimitación Del obJeto}

Comprender el funcionamiento del sistema jurídico requiere de la comprensión previa de las normas de competencia, por lo que la relevancia de su análisis no requiere de justificación, aun cuando ya ha sido estudiado por varios autores desde distintos puntos de vista.

$\mathrm{Si}$ el derecho es concebido como un sistema normativo de carácter dinámico, las normas de competencia pueden ser consideradas como uno de sus elementos básicos o primarios. De tal forma que, si se acepta su papel primordial en el sistema jurídico, es preciso determinar su status normativo para poder comprender su alcance en el ejercicio, así como las consecuencias del mismo para el sistema jurídico. Las normas de competencia constituyen el origen de otras normas del sistema jurídico, y por ende un elemento determinante de la validez de los procesos de creación. El concepto de competencia se encuentra por lo tanto estrechamente relacionado con el de validez, no solamente de las normas jurídicas, sino del sistema mismo.

El objetivo es revisar la discusión en torno al carácter deóntico de las normas de competencia, entendidas éstas como las normas que atribuyen alguna facultad a un sujeto con carácter de autoridad únicamente. Esto implica distinguir distintos tipos de enunciados normativos para revisar su carácter deóntico, y analizar su función, esto es, aquello que pueden realizar en el marco de un sistema jurídico.

La explicación de la norma de competencia requiere del examen de su estructura y la distinción de sus funciones en el sistema jurídico, aun cuando su función de norma fundante (o fundamental como la denomina Kelsen) ${ }^{1}$ no será analiza207.

1 Kelsen, Hans, Allgemeine Theorie der Normen, Viena, Manz Verlag, 1990, p. 
da en esta ocasión. ${ }^{2}$ Analizar su carácter deóntico servirá para determinar su naturaleza jurídica, lo cual a su vez depende del concepto mismo de competencia. Ésta a su vez, ha de ser entendida como facultad que posibilita el ejercicio del poder atribuido a la autoridad por el sistema jurídico.

Para ello es necesario adoptar un concepto específico de norma que permita desarrollar el análisis de los distintos tipos de normas, con el objeto de diferenciar las normas de competencia y tipificarlas. A tal efecto se analizan los elementos componentes de las normas de acuerdo con la clasificación de von Wright, ${ }^{3}$ para poder responder a la pregunta sobre si las normas de competencia tienen un contenido o sujeto específico, y para determinar su carácter y contenido.

A efecto de establecer el marco conforme al cual se hará el planteamiento, se propone un concepto semántico de norma y se define la función de la norma de competencia como norma secundaria en el sentido de Hart. La idea de identificar el carácter deóntico de las normas de competencia tiene por objeto evaluar el modo de exigir su realización y de atribuir consecuencias jurídicas en caso de omisión. Esto, sin embargo, depende de las diversas posibilidades de interpretación del carácter de la norma de competencia como permiso, como obligación para ejercer una cierta atribución, o como un deber cuyo ejercicio depende de una situación determinada, por ejemplo.

La competencia se analiza como "poder normativo", 1o cual la vincula con la noción de "deber"; 4 es en este sentido que debe investigarse su relación con el concepto de deber (Sollen). La competencia, por lo tanto, ha de entenderse

2 En realidad no se puede excluir completamente la referencia a las normas fundantes, pero en esta ocasión solamente se hará de manera tangencial a efecto de distinguir la norma de competencia de su contenido.

3 Wright, G. H. von, Norma y acción. Una investigación lógica, trad. de Pedro García Ferrero, Madrid, España, Tecnos, 1979, pp. 87 y ss. (título original: Norm and Action. A Logical Enquiry, Londres, Routledge and Kegan Paul, 1963).

4 MacCormick señala que no es un poder de hecho, sino de otro tipo. Véase MacCormick, Neil, "Law as Institutional Normative Order", Rechtstheorie 28, Berlin, Duncker und Humblot, 1997, p. 222. 
como poder jurídico o facultad. Por su contenido, es posible distinguir dos tipos de normas de competencia: las que atribuyen competencia al órgano emisor de una norma (facultan en sentido estricto) y las que regulan el procedimiento de creación. Para poder comprender dicha clasificación es preciso distinguir entre las normas que facultan a las autoridades de las que no lo hacen. La postura que sostiene que el derecho solamente puede ser explicado si se distingue entre las normas que atribuyen competencia y las que obligan o establecen deberes, pertenece a una de las más importantes tesis de la filosofia del derecho contemporánea. ${ }^{5}$

Se considera que los sistemas jurídicos son estructuras que esencialmente consisten de dos tipos de normas: las que imponen deberes (duty-imposing norms) y las que atribuyen poderes para emitir normas (power-conferring norms). ${ }^{6}$ Esta afirmación ha llevado a sostener que el derecho solamente puede ser entendido a partir de una distinción precisa entre estos dos tipos de normas. Según Ross, un sistema jurídico bien desarrollado, siendo institucional y dinámico, contiene normas de conducta que prescriben cómo actuar y normas de competencia que proveen cómo nuevas normas válidas y vinculantes pueden ser creadas mediante la ejecución de actos jurídicos. ${ }^{7}$ Por lo anterior, resulta indispensable esclarecer el significado del concepto de facultad o facultamiento (empowerment).

Hart ${ }^{8}$ indica que la distinción entre el derecho y otros sistemas normativos radica en que el derecho contiene diferentes

5 Hart, H. L. A., The Concept of Law, 2a. ed., Oxford, Clarendon Series, Oxford University Press, 1979, especialmente los capitulos 3-6; Raz, Joseph, The Concept of a Legal System, Oxford, Oxford University Press, 1970, especialmente los capitulos 4-6.

6 Así las denomina MacCormick al señalar que "cuando representamos un orden normativo de manera dinámica, lo representamos en términos de las normas que regulan el cambio, individualizadas como normas de competencia, power-conferring rules, reglas institutivas de instituciones jurídicas. Véase "Law as Institutional Normative Order", loc. cit., nota 4, p. 233.

7 Ross, Alf, Directives and Norms, Londres, Routledge and Kegan Paul, 1968, p. 118 .

8 Hart, The Concept of Law, cit., pp. 101. 
tipos de normas, ya que no solamente prescribe conductas (normas primarias), sino que también prevé una serie de normas que se refieren a esas normas y a los órganos de creación y aplicación (normas secundarias). Según Hart, forma parte de esta segunda clase: la "regla de reconocimiento", que permite determinar qué normas pertenecen al sistema; la "regla de cambio", que establece los órganos y los procedimientos de creación normativa - fundamental en virtud de la dinámica del derecho-, y la "regla de adjudicación", que establece los órganos y procedimientos de aplicación. No obstante, esta forma de agrupar las normas no implica la supresión del carácter prescriptivo de las normas secundarias, ya que ambos tipos de normas tienen la misma estructura lógica y son obligatorias. El objetivo de esta distinción es subrayar el hecho de que en los sistemas jurídicos existen normas que se refieren al propio sistema, ya que otros tipos de normatividad solamente establecen normas que se dirigen a los individuos (normas de conducta, s.s.).

\section{Posturas Doctrinales}

Para abordar la cuestión del status jurídico de las normas de competencia, esto es, si son normas de conducta, si tienen una estructura especial o si realizan una función especial, se revisarán tan sólo algunas teorias a fin de compararlas y buscar una respuesta adecuada. Se ha elegido como referentes a Kelsen, Bulygin y von Wright, no solamente por su vinculación teórica, sino sobre todo porque, en mi opinión, ofrecen los elementos necesarios para poder aportar algunas conclusiones. ${ }^{9}$

El concepto de norma de competencia es entendido como la norma prevista en un enunciado normativo válido san-

9 Aun cuando existen numerosos trabajos realizados en los últimos años, como son los de Ruiter (Institutional Legal Facts. Legal Powers and their Effects, Dordrecht, Kluwer,1993), Spaak (The Concept of Legal Competence, Aldershot, Dartmouth, 1994) o Ferrer (Las normas de competencia. Un aspecto de la dinámica jurídica, Madrid, CEPC, 2000), prefiero restringirme a estos tres autores como fuentes directas de la problemática que se analiza. 
cionado por la autoridad que atribuye facultades de derecho público a un sujeto determinado por su carácter de funcionario. De esta manera se distingue de las facultades que forman la capacidad jurídica de las personas en el derecho privado, que se integra por sinnúmero de derechos.

\section{La postura de Kelsen}

En la Teoría general de las normas, Kelsen señala que el término norma en la lengua alemana procede del latín y que "designa - aunque no de manera exclusiva, pero si de manera preeminente- una obligación (Gebot), una prescripción (Vorschrift), una orden (Befehl)". En su opinión, las normas jurídicas son prescripciones referentes al comportamiento mutuo entre los hombres. ${ }^{10}$ Según Kelsen, obligar no es la única función de las normas; facultar (ermächtigen), permitir y derogar también son funciones de las normas. ${ }^{11}$ Una de las preguntas que se podría derivar de sostener que las normas jurídicas cumplen funciones distintas, es si pueden ser distinguidas por ciertos elementos característicos o en la forma del enunciado según su función.

Las normas de competencia se encuentran en el núcleo de la teoría del sistema jurídico dinámico de estructura escalonada de Kelsen, puesto que las normas de un sistema forman una unidad dinámica que se encuentra determinada por una norma última de referencia que constituye el parámetro de validez de sus normas. La Norma Fundamental de Kelsen, que sirve como criterio de pertenencia y validez de las normas del sistema, es en sí misma una norma de competencia. La Constitución, entendida como la primera norma positiva de un sistema jurídico, determina los procesos de creación y modificación del sistema. Para Kelsen, esta norma suprema regula órganos, procedimientos y contenidos. Las dos primeras categorias apuntan a normas

10 Kelsen, Hans, Teoría general de las normas, México, Trillas, 1994. p. 19.

11 Kelsen, Allgemeine Theorie der Normen, cit., p. 1. 
de competencia y determinan la validez formal de las normas secundarias; la tercera, en cambio, es relativa a la validez material de las normas creadas a partir de las normas de competencia prevista en la Constitución.

Esta cualidad de norma de competencia de la Constitución puede apreciarse de manera clara en la afirmación de Bulygin, el cual sostiene que todo sistema jurídico tiene por definición una primera Constitución. Para Bulygin, "cualquier conjunto de normas que contenga por lo menos una norma de competencia puede ocupar la posición de una primera Constitución y dar lugar a un sistema jurídico". ${ }^{12} \mathrm{De}$ igual modo se puede describir la Norma Hipotética Fundamental de Kelsen, cuyo carácter es puramente competencial, ya que como fundamento de validez contiene la competencia del constituyente, por ejemplo, de la primera norma positiva constitutiva de un sistema jurídico que, entre otras normas, debe contener como mínimo una norma de competencia que legitime jurídicamente el desarrollo del sistema.

Debido a la caracterización de la Constitución como norma primera y superior del proceso de creación normativa que prevé normas de competencia, ésta puede, en la medida en que sea una norma positiva, ser considerada como el primer criterio de validez de todo el sistema jurídico. Al mismo tiempo puede proporcionar un criterio de pertenencia de las normas a un orden jurídico específico. Esta misma relación se establece entre la "regla de reconocimiento" de Hart y las normas de un sistema jurídico, ya que ésta constituye un criterio para la calificación de la Constitución. Por lo cual se podría identificar a la Constitución como regla de reconocimiento al regular los procesos de creación y modificación del sistema. Por su parte, Raz añade $^{13}$ que en un sistema jurídico existe más de una regla de

12 En este caso Bulygin utiliza el concepto de orden, sin embargo, en virtud de que se refiere a la totalidad de las normas y de que por sus propiedades definitorias me parece más adecuado el término de sistema, utilizo éste para ello. Véase Bulygin, E., "Algunas consideraciones sobre los sistemas jurídicos", Doxa, 9, 1991, pp. 263 y 264.

13 Raz, Joseph, The Concept of a Legal System, cit., p. 239. 
reconocimiento, por lo que resulta posible que en un sistema jurídico específico exista más de una fuente de las normas de competencia.

La teoría de Kelsen se centra en el aspecto formal y dinámico del derecho; en los procedimientos de creación y aplicación de las normas. Y es precisamente en esta distinción donde se aprecia el carácter especial de las normas de competencia, ya que hace posible distinguirlas de las normas que regulan la conducta de los particulares (o normas de conducta, simplemente). El derecho no solamente es dinámico, sino que regula su propia dinámica estableciendo los limites y alcances de la misma, lo cual constituye uno de los rasgos distintivos de este tipo de normatividad.

Kelsen delimita el concepto de competencia a partir de los conceptos de órgano y de imputación. Para él, "la persona que cumple una función determinada por el orden jurídico tiene el carácter de órgano. Tales funciones, sean de creación o de aplicación de normas, tienden, en última instancia, a la ejecución de una sanción jurídica". En su opinión, "el concepto estricto, material de órgano, tiene su contrapartida en otro concepto estricto y material de imputación al Estado". ${ }^{14}$ La relación que se produce entre el supuesto de hecho y la sanción a través de la cópula, es la de imputación normativa, que es similar a la de consecuencia lógica y que deriva de la estructura condicional de la norma jurídica. ${ }^{15}$ La facultad atribuida por una norma de competencia a un individuo (funcionario) le atribuye, por lo tanto, la especial calificación de órgano al facultarlo para realizar funciones específicas.

Para Kelsen un funcionario "debe" ejercer la competencia atribuida, ya que "el ejercicio de su función es contenido de una obligación específica, el deber correspondiente al cargo,

14 Kelsen, H., Teoría general del derecho y del Estado, segunda edición de 1958, trad. de Eduardo García Máynez, México, UNAM, 1988, p. 229.

15 Kelsen, Reine Rechtslehre (primera edición de 1934), Darmstadt, Scientia Verlag Allen, 1994, p. 22; Reine Rechtslehre (segunda edición de 1960), Viena, Franz Deuticke, 1983, pp. 40, 79 y ss.; García Máynez, Introducción al estudio del derecho, México, Porrúa, 1982, pp. 174-176. 
cuyo cumplimiento se garantiza mediante medidas disciplinarias". ${ }^{16}$ Este hecho apunta hacia su cualidad de norma imperativa que establece un deber ser, cuyo carácter es obligatorio, por lo que las normas de competencia no parecen ser potestativas para Kelsen. En su obra póstuma, señala de manera expresa que "la función normativa de atribuir competencia es distinta a las funciones de permitir y de obligar. Pero que facultar (ermächtigen) puede implicar obligar. Implica una obligación, cuando se atribuye competencia para emitir normas". ${ }^{17}$

Por otra parte, el concepto de sanción, como la posibilidad de vincular un acto coactivo con un acto ilícito o contrario a lo dispuesto en una norma, es central para el derecho en la teoría de Kelsen. ${ }^{18}$ La sanción, sin embargo, como elemento de la norma, puede ser entendida como las consecuencias jurídicas atribuidas por la norma jurídica - esto es, derechos y obligaciones-, la cual puede ser de carácter premial o punitivo y estar enlazada con un acto coactivo, atribuir potestades, o determinar responsabilidad. La nulidad puede ser considerada, por lo tanto, como la consecuencia jurídica del incumplimiento de las condiciones de validez de una norma, por lo que en este sentido puede ser considerada como sanción al acto inválido que se encuentra prevista en otra norma.

Para la teoría de Kelsen, las normas de competencia se encuentran agrupadas con las normas secundarias, que en su terminología implica que establecen una conducta y que dependen de una norma que determine una consecuencia jurídica para el caso de su incumplimiento. ${ }^{19} \mathrm{La}$ distinción material entre normas primarias (que prevén una sanción coactiva) y secundarias (de deber, l.s.) refleja claramente su idea de un sistema jurídico como unidad, en

16 Teoría pura del derecho, 2a. ed. de 1960, trad. de Roberto J. Vernengo, México, Porrúa, 2000, p. 300.

17 Kelsen, Allgemeine Theorie der Normen, cit., p. 83.

18 Kelsen, Teoría pura del derecho, 2a. ed., cit., pp. 123 y ss.

19 Las normas secundarias, según Kelsen, son incompletas porque no prevén una sanción, Kelsen, Teoría pura del derecho, 2a. ed., cit., pp. 67-70. 
el cual sus normas se relacionan para darle sentido. La comprensión de las normas de competencia depende también de sus relaciones internas con otras normas. Concebir al sistema jurídico como un conjunto coherente de normas que se relacionan entre sí es, en mi opinión, una condición de la posibilidad de la determinación de su significado.

Según la tesis de la norma jurídica no independiente de Kelsen, ${ }^{20}$ las normas se relacionan en función de la unidad del sistema jurídico de manera que todos sus enunciados pueden conectarse de manera más o menos directa con una sanción coactiva, y su cumplimiento, en consecuencia, es potencialmente coercible. Por lo que resulta posible afirmar que todos los enunciados de un sistema jurídico tienen carácter normativo, ya que establecen alguna forma de deber ser y en consecuencia son obligatorios. Al hacer una interpretación sistemática se pueden establecer las consecuencias jurídicas de un supuesto y determinar qué normas son completas, o en su caso, cómo se relacionan para conectar un supuesto con sus consecuencias jurídicas. Los principios que rigen el funcionamiento del sistema jurídico, así como el propio orden jurídico determinan la forma en que los elementos de la norma se relacionan debidamente.

Considero importante retomar la idea de que las normas de un sistema jurídico se encuentran vinculadas con otras normas que, a su vez, determinan las consecuencias jurídicas de su satisfacción o incumplimiento. Sobre todo porque en el caso de las normas de competencia se produce la responsabilidad jurídica del funcionario como consecuencia de su incumplimiento y puede acarrear la invalidez del acto. Alchourrón y Bulygin critican la definición de norma de Kelsen en función de su propia definición de norma en términos de relación entre un caso y su solución, por lo que intentan demostrar que no todos los enunciados normativos tienen una sanción, entendida en términos de eje-

20 Kelsen, Hans, Reine Rechtslehre, cit., pp. 52, 55 y ss., Teoría pura del derecho, cit., pp. 67-70. 
cución de un acto coactivo. ${ }^{21}$ Vale la pena señalar que la definición de solución propuesta por Alchourrón y Bulygin es, sin embargo, compatible con la de consecuencia juridica, lo cual en última instancia permite vincular un caso con una sanción/acto coactivo en términos de la tesis de las normas no independientes de Kelsen.

\section{La perspectiva de Bulygin}

Alchourrón y Bulygin abordaron el problema de la competencia en Introducción a la metodología de las ciencias juridicas y sociales a partir del análisis de la permisión, distinguiendo el permiso fuerte del débil, o el positivo del negativo como los denominaron respectivamente. ${ }^{22}$ Esta distinción es de gran relevancia para explicar la identificación que se hace en esta obra de la competencia con la permisión. ${ }^{23} \mathrm{El}$ análisis de la permisión se hará posteriormente en relación con la determinación del carácter deóntico de las normas de competencia.

Estos autores distinguen dos tipos de normas, o sistemas de normas como ellos lo denominan, de conformidad con el sujeto normativo a quienes se dirigen los enunciados normativos, diferenciando las normas que se dirigen al juez de las que se dirigen a los particulares, aunque consideran que se trata de sistemas que se interrelacionan. ${ }^{24} \mathrm{El}$ "sistema primario o del súbdito" se integra por reglas de conducta, y el "sistema secundario o del juez" regula su actividad como funcionario, y se integra por dos tipos de normas: las

21 Alchourrón y Bulygin, Normative Systems, Viena-Nueva York, Springer Verlag, 1971, p. 59, e Introducción a la metodología de las ciencias juridicas y sociales, Argentina, Editorial Astrea, 1987, pp. 97 y 98.

22 Alchourrón y Bulygin, cit., pp. 171 y ss.

23 La concepción de las normas de competencia como normas permisivas en Alchourrón y Bulygin se sigue de las tesis de von Wright, Norma y acción, cit., pp. 198 y ss.

24 Hablan así del sistema del juez o secundario y el sistema del súbdito o sistema primario, en Normative Systems, cit., pp. 144-155, y Introducción a la..., cit., pp. 205, 208 y ss. 
de competencia y las de obligación. ${ }^{25}$ Las normas de competencia le confiere a los jueces la facultad de juzgar, esto es, la jurisdicción en términos de Alchourrón y Bulygin. El otro tipo de normas les impone obligaciones y prohibiciones a los jueces y consideran que también son normas de conducta, pues regulan su conducta como jueces, es decir, en el ejercicio de su función jurisdiccional. ${ }^{26}$ En mi opinión, sin embargo, esta distinción no priva de su carácter prescriptivo a las normas que integran el sistema del juez, ya que según los autores citados, tanto las normas de competencia (que regulan la facultad de juzgar) como las normas que establecen obligaciones y prohibiciones constituyen normas de conducta para el juez. ${ }^{27}$

Para estos autores, "las normas de competencia son normas de conducta para los jueces, si se las concibe como normas permisivas que establecen la permisión de realizar ciertos actos en ciertas circunstancias". 28 Pero aclaran, "que al mismo tiempo son constitutivas de la autoridad judicial", ya que el carácter de juez deriva de una norma de competencia, "en la medida y con el alcance que la norma determine". ${ }^{29}$ Con esta afirmación se manifiesta una primera ambigüedad -o quizá tan sólo una cierta inquietud por explicar las normas de competencia de una manera distinta-. En el fondo, creo que lo que se refleja aquí es la insatisfacción de la explicación de este tipo de normas como

25 Citan como ejemplo de regla de conducta, la obligación de juzgar, y la de fundar la decisión; cfr. Introducción a la ..., cit, pp. 211-214. En Definiciones y normas, Alchourrón y Bulygin sostienen que los jueces no solamente deben realizar las conductas exigidas por las leyes, sino además deben justificar sus decisiones en las normas jurídicas, y que esta obligación deriva de las normas sustantivas, no de las definitorias; $c f$. Análisis lógico y derecho, Madrid, Centro de Estudios Constitucionales, 1991, p. 451.

26 Alchourrón y Bulygin, Introducción a la ..., cit., p. 210, y Bulygin, "Sobre las normas de competencia", Análisis lógico y derecho, Madrid, Centro de Estudios Constitucionales, 1991, p. 497.

27 Alchourrón y Bulygin, Introducción a la ..., cit., p. 208.

28 Ibidem, pp. 208 y 209.

29 Idem. 
normas permisivas. ${ }^{30}$ Por otra parte, vale la pena recordar que la autoridad judicial es constituida por el nombramiento, una norma jurídica individual que procede de la competencia de otra autoridad normativa, además de que las normas de competencia atribuyen facultades y delimitan su ejercicio, pero no "definen" (en sentido estricto del término), el carácter de juez. No se limitan a describir una situación o a atribuir significado, sino que atribuyen facultades, constituyen la jurisdicción del juez.

Alchourrón y Bulygin sostienen que "las normas de competencia son (una clase especial de) normas permisivas; son normas de conducta que permiten crear nuevas normas". ${ }^{31}$ Por lo cual supongo que no pueden ser consideradas como normas permisivas en el sentido general del término, como facultad de hacer o no hacer libremente, pues contienen algo que las hace distintas. Sin embargo, señalan que estas reglas a pesar de ser permisivas, en realidad "no son normas de conducta, sino meras definiciones", 32 al igual que los criterios de identificación, lo cual parece indicar una contradicción. Sobre todo porque insisten en distinguir este tipo de criterios de las reglas de competencia aunque hagan referencia a ellas.

Por otra parte, consideran que los enunciados que prevén normas de competencia son normas que autorizan a formular enunciados válidos en un sistema jurídico, pero para establecer la validez de un enunciado, en su opinión, es necesario conocer el contenido de ciertas normas de competencia. El contenido de las normas de competencia a que se refieren estos autores es el de las normas que fundamentan la creación de una norma cuya validez es cuestionada. En este sentido se puede decir, sin embargo, que aun cuando las normas de competencia hacen posible la emisión de

30 En 1983 Alchourrón y Bulygin reconsideran este planteamiento para explorar una explicación de las normas de competencia en términos de reglas conceptuales, en "Definiciones y normas", publicado en Análisis lógico y derecho, cit., pp. 462 y 463.

31 Alchourrón y Bulygin, Introducción a la ..., cit., p. 120.

32 Ibidem, p. 121. 
enunciados válidos, no aseguran la validez en términos de su obligatoriedad definitiva de los mismos, ya que la validez jurídica de las normas tan sólo tiene un carácter prima facie.

Posteriormente Bulygin revisa esta postura en Sobre las normas de competencia, ${ }^{33}$ y hace un análisis de diversas posturas doctrinales (Kelsen, Hart, Ross, von Wright, Lindahl) a efecto de determinar la naturaleza de las normas que confieren competencia, esto es, poderes o potestades, y que hacen posible la creación de normas que pueden producir efectos jurídicos. Kelsen distingue, por ejemplo, la competencia como poder para crear normas jurídicas por órgano con motivo del ejercicio de una función atribuida, de la capacidad jurídica para crear normas que obligan a las personas que las emiten o para producir ciertos efectos jurídicos. Así, señala Bulygin, que "las normas de competencia son las que establecen esa capacidad (de crear normas jurídicas o producir efectos jurídicos) señalando las condiciones necesarias para su ejercicio. ${ }^{34}$

Para ello, Bulygin procede a distinguir la competencia del permiso, aclarando que no pueden ser identificadas, porque deben diferenciarse las normas de conducta (o deber, en mi opinión), ya sean de obligación o prohibición (imperativas, s.s.) o de permiso (facultativas/potestativas, en un sentido muy amplio, que permite decidir entre la realización o no realización de la acción), de las normas "constitutivas", que según él, no imponen deber alguno. En relación con estas últimas, Bulygin sigue a Hart, para el cual las normas de competencia (reglas que confieren potestades) no son reducibles a normas de conducta (entendidas como órdenes seguidas de amenazas). ${ }^{35}$ Asimismo, utiliza la clasificación propuesta por Ross, en Directives and Norms, que permite distinguir entre reglas regulativas y constitutivas. ${ }^{36}$ Por otra

33 En Alchourrón y Bulygin, Análisis lógico y derecho, cit., p. 489.

34 Ibidem, "Sobre las normas ...", cit., p. 487.

35 Hart, The Concept of Law, p. 41.

36 Ross, Alf, Directives and Norms, cit., pp. 54 y ss. 
parte, Bulygin señala que para Searle, "las normas constitutivas no sólo regulan, sino que "crean o definen nuevas formas de conducta". 37 Aquí Searle apunta un aspecto relevante para la determinación de la naturaleza de las normas de competencia: su función es regular; por lo tanto, son normas, y su objeto son necesariamente conductas. Sin embargo, a Bulygin no le parece posible que las reglas constitutivas sean definiciones o enunciados analiticos ${ }^{38}$ al mismo tiempo que normas regulativas de las actividades que prevén. ${ }^{39}$ Sobre todo porque, en su opinión, una misma regla no puede ser a la vez una regla conceptual (una definición) y una norma de conducta (una prescripción), por lo que la observación de Searle le parece equivoca. ${ }^{40}$

Al evaluar la tesis de von Wright, Bulygin señala que "la idea de que las normas de competencia son normas permisivas es difícilmente conciliable con la práctica jurídica". ${ }^{41}$ Con lo cual estoy de acuerdo, sobre todo porque de ser permisivas su ejercicio sería optativo y, en el caso de existir en el sistema jurídico una norma que obligue a ejercer la competencia, se produciría necesariamente un conflicto entre estas dos normas que solamente se puede resolver considerando la competencia como una facultad de ejercicio obligatorio, por lo que no puede ser considerada como una norma permisiva en sentido estricto. Es por ello que Bulygin señala que "parece más promisor (sic) intentar una explicación en términos de reglas conceptuales o constitutivas". Así, las normas de competencia definen el concepto de legislador y

37 Searle, John R., Speech Acts. An essay in the Philosophy of Language, Cambridge, U. K., Cambridge University Press, 1969, p. 33, citado por Bulygin en "Sobre las ...", cit., p. 492 .

38 En este mismo artículo Bulygin sostiene que las normas de competencia no son semejantes a las normas de conducta, sino criterios conceptuales, apoyándose en la distinción entre proposiciones analíticas y sintéticas. Bulygin, "Sobre las ...", cit., pp. 495-497. Además señala Bulygin en Definiciones y normas que las normas deben ser sintéticas aun cuando no sean descriptivas pues su función es regular conductas, cit., p. 459.

39 Bulygin, "Sobre las ...", cit., p. 492.

40 Ibidem, p. 494.

41 Ibidem, p. 489. 
"hacen posible la actividad de legislar". ${ }^{42}$ Pero agrega que además de este tipo de normas, puede haber normas de conducta que regulen actividades de la autoridad competente que no son necesariamente definitorias de su cualidad de funcionario (permisos, derechos, inmunidades, etcétera). 43

Bulygin señala que "la definición consiste en indicar las características esenciales o definitorias que debe reunir un objeto para que el término definido sea aplicable". ${ }^{44}$ Pero las "definiciones legales", más que definir, tienen por objeto explicitar los elementos del supuesto que son necesarios para que se pueda considerar que una acción o estado de cosas se encuentra en aptitud de ser subsumido en el supuesto de hecho de un enunciado normativo para la atribución de las consecuencias jurídicas previstas. Pues como señalaba Carrió, "las definiciones que aparecen en textos legales producen efectos normativos, y por ende, son una especie de norma", 45 dado que una norma expresa que una conducta debe ser, ya sea de manera prohibida, permitida u obligatoria.

Desde la perspectiva de Alchourrón y Bulygin, las normas son el sentido expresado por los enunciados lingüísti$\operatorname{cos;46}$ para ellos, si una "norma definitoria" obliga a usar una definición, entonces la definición sería distinta de la norma. ${ }^{47} \mathrm{De}$ tal forma, el enunciado normativo parece tener dos significados: uno implícito, que prevé una norma que establece la obligación de entender un término en el sentido previsto; y otro explícito, que establece una definición, ya sea que introduzca un término, lo aclare o precise su alcance. Estos autores señalan que en virtud de la función prescriptiva de los enunciados normativos, las definiciones lega-

42 Ibidem, pp. 496 y 497.

43 Ibidem, p. 497.

44 Alchourrón y Bulygin, "Definiciones y normas", cit., p. 457.

45 Ibidem, p. 439.

46 Ibidem, p. 442.

47 Se entiende por "definición legal", el enunciado normativo válido que prescribe el sentido y alcance jurídico de un término para poder producir los efectos jurídicos que se prevén en el cuerpo normativo que lo prevé. 
les no son meramente informativas, sino estipulativas - esto es, estipulan el significado de la expresión ${ }^{48}$ (aunque solamente para efectos jurídicos)—. Por lo tanto, no son ni verdaderas ni falsas, a diferencia de las definiciones doctrinales, o las definiciones de los jueces, según Alchourrón y Bulygin, las cuales, sin embargo, considero que también son prescriptivas, por lo que no pueden ser verdaderas, ni calificadas como simples definiciones. Para ellos las definiciones sirven para "identificar" otras normas (al enlazar y complementar los enunciados normativos para determinar su significado), y la identificación de las normas es condición para su aplicación, por lo que el órgano aplicador debe usarlas. ${ }^{49}$ Señalan, sin embargo, que este deber se entiende como "regla técnica", que sirve al que quiere aplicar la norma a identificarla.

Alchourrón y Bulygin sostienen que "las definiciones legales" no son normas de conducta, ni reglas técnicas, aunque pueden dar lugar a la formulación de estas últimas y que su función radica en la identificación de normas. ${ }^{50}$ Pero las definiciones legales no solamente producen efectos normativos cuando su modificación implica el cambio de calificación normativa de una acción o estado de cosas como señalan, 51 sino principalmente por su vinculación con los supuestos que prevén los conceptos jurídicos que regulan. Por lo que las considero normas en sentido estricto, o fragmentos de normas en su caso, ya que permiten enlazar el supuesto de hecho que prevén con otras normas para producir efectos jurídicos. Pero no considero, como ellos, que la función de las definiciones legales sea servir para entender el lenguaje usado por el legislador, ${ }^{52}$ porque su función es producir la imputación de consecuencias jurídicas a los

48 Ibidem, p. 447.

49 Ibidem, pp. 448 y 449.

50 Ibidem, p. 453.

51 Idem.

52 Ibidem, p. 455. 
actos regulados, no dar explicaciones, aun cuando dan sentido a la normas en la interpretación sistemática.

Las normas son, para Alchourrón y Bulygin, los enunciados que correlacionan un caso con una solución, es decir, una decisión jurídica. ${ }^{53}$ En consecuencia, sostienen que en el derecho existen diversos tipos de enunciados, entre los cuales se encuentran algunos que a pesar de formar parte del sistema jurídico carecen de carácter normativo. ${ }^{54} \mathrm{La}$ apreciación de que pueden existir enunciados sin carácter normativo no es exclusiva de los autores mencionados. ${ }^{55}$ Esta percepción se funda en el hecho de que en los sistemas jurídicos frecuentemente se encuentran enunciados que dificilmente parecen normas en sentido estricto. El análisis estructural del enunciado normativo, sin embargo, sirve para la identificación de sus elementos, pero requiere de una concepción adecuada del sistema jurídico como unidad, y que la sanción no sea concebida exclusivamente como acto coactivo, sino como consecuencia jurídica, para poder considerar que sus enunciados pueden generar derechos u obligaciones.

Alchourrón y Bulygin mencionan 3 tipos básicos de enunciados: los enunciados que prescriben un acto coactivo; los que ordenan, prohíben o facultan y permiten, pero no establecen una acto coactivo (en este grupo incluyen las normas de competencia), y los que no son enunciados normativos y no tienen efectos normativos que pueden ser de 2 clases: los que influyen en los efectos normativos de otros

53 Alchourrón, Carlos y Bulygin, E., Introducción a la metodología de las ciencias jurídicas y sociales, cit., pp. 71 y ss.

54 Su opinión se funda en el criterio de identificación del sistema que utilizan: "A normative set is a set of sentences such that among its consequences there are some sentences that correlate cases with solutions. Every normative set which contains all its consequences will accordingly be called a normative system". Cit., pp. 54 y 55, 58, 69. Para ellos, las normas son los enunciados que correlacionan casos (circunstancia en que interesa saber si una acción está permitida, ordenada o prohibida por un sistema normativo) con soluciones (las respuestas que el sistema emite), ibidem, pp. 37, 52, 71 y 72,86 y ss.

55 Atienza y Ruiz Manero, basados en la definición de norma que proponen, afirman que no todos los enunciados de un sistema son normas, Las piezas del derecho, Teoría de los enunciados jurídicos, Barcelona, Ariel Derecho, 1996, pp. 54 y ss. 
enunciados, como las "normas definitorias" y las derogatorias; (enunciados que, a mi parecer, son normas jurídicas que prescriben conductas que se refieren a sujetos normativos específicos y que en caso de su infracción tienen consecuencias jurídicas), y los que no tienen influencia alguna y cuya eliminación sería deseable. 56

Pero entonces, ¿qué es una norma de competencia? Al analizar las normas de competencia, Bulygin propone un ejemplo para determinar si son permisiones - lo que no me parece del todo adecuado, ya que no permite distinguir la capacidad de la competencia, ni considero que en ese caso la prohibición del ejercicio de la capacidad produzca una contradicción en el orden jurídico-. ${ }^{57}$ En dicho ejemplo la facultad para actuar como abogado, propia del individuo en virtud de una personalidad jurídica, y la posibilidad de ejercerla, es suprimida en virtud de la adquisición del carácter de juez. La competencia que deriva del nombramiento que depende del derecho público corresponde al sujeto que ejerce el cargo en virtud de ello, pero no es una facultad que se le atribuye por su persona. En realidad este ejemplo presenta el carácter de un conflicto entre normas, entre dos reglas específicamente, en virtud de lo cual por excepción se limita la capacidad jurídica de una persona, un abogado, al adquirir la cualidad de juez para realizar ciertos actos como abogado. La incompatibilidad entre las normas produce una limitación temporal de la norma que regula las facultades de los letrados. De lo dicho se sigue que el concepto de competencia en Bulygin parece referirse más bien a una "aptitud jurídica" en sentido muy amplio, entendida como posibilidad de realizar actos calificados jurídicamente y que produzcan las consecuencias jurídicas previstas en el sistema. Esto implica que la modalidad deóntica de la facultad de actuar de un particular sería la misma que la facultad atribuida a un funcionario público como parte de su competencia.

56 Alchourrón y Bulygin, Introducción a la ..., cit., pp. 106 y 107.

57 Bulygin, "Sobre las...", cit., p. 489. 
Bulygin propone como criterio para diferenciar una norma de competencia (definitoria o constitutiva) de una norma de conducta: la posibilidad de que un poder jurídico (facultad o capacidad) subsista a pesar de la prohibición de ejercerla, como sería el caso de la norma de competencia, mientras que si la facultad desaparece tras la prohibición, su carácter era el de una norma permisiva. ${ }^{58}$ Este criterio solamente parecer ser útil, si en el concepto de competencia se incluye a la capacidad jurídica (s.s.), pues se confunden la capacidad y la competencia. En este ejemplo, la capacidad se ve modificada y parcialmente suspendida de manera excepcional y temporalmente, por la adquisición de la competencia. ${ }^{59}$ Es preciso, por lo tanto, distinguir la capacidad de la competencia, esto es, las facultades de los individuos para realizar actos jurídicos y que se produzcan consecuencias jurídicas, de las atribuciones de la autoridad que los faculta para realizar actos normativos o de ejecución.

No obstante lo señalado, el propio Bulygin cuestiona la posibilidad de considerar a las normas de competencia como definiciones en la Introducción a Análisis lógico y derecho, ${ }^{60}$ al señalar que:

La idea de que las llamadas normas de competencia no puedan reducirse a normas de conducta por contener un ingrediente definitorio parece sana, pero no es muy claro si tales normas pueden reducirse a meras definiciones. Las normas permiten considerar un hecho o un acto como jurídicos y lograr la atribución de las consecuencias jurídicas en virtud de la imputación, en esa medida se pueden considerar "calificatorias", lo cual puede llevar a considerar a las normas jurídicas como definitorias o conceptuales.

Pero su función no se limita a calificar una situación jurídica cuando atribuye facultades, y aun si fuese asi, enlazan

58 Ibidem, p. 497.

59 En realidad, aun así, no estoy segura de la utilidad de este criterio.

60 Esta Introducción es publicada en 1991, tan sólo tres años después de la aparición del artículo citado de Eugenio Bulygin sobre las normas de competencia. 
enunciados normativos de tal forma que una norma pueda producir efectos jurídicos.

Finalmente, vale la pena señalar que la distinción entre nulidad y sanción en términos de Bulygin no sirve como criterio suficiente para considerar que las normas de competencia son definitorias, sobre todo porque la validez no es parte de la norma, sino una cualidad que las normas deben poseer si pretenden producir efectos jurídicos. Las definiciones explican, no producen consecuencias, ni siquiera las mal llamadas "definiciones legales", sobre todo porque para ello dependen del supuesto de una norma que se enlaza con los enunciados normativos que prevén el término en cuestión. Por lo que, según Kelsen, podrian ser consideradas como normas secundarias o no independientes, o como Bulygin prefiere considerarlas, como partes o fragmentos de una norma. 61

\section{La tesis de von Wright}

Von Wright sostiene que las normas de competencia son normas de conducta de carácter permisivo, pero las califica como normas de segundo orden puesto que su contenido es un acto normativo (sea de emisión o eliminación de una norma), esto es, normas cuyo sujeto normativo es una autoridad normativa de orden inferior. Pertenecen, entonces, a un orden superior y los actos normativos pueden estar calificados deónticamente como obligatorios, prohibidos o permitidos. Las normas de competencia son para él permisos de orden superior que se emiten para que una autoridad específica pueda dar normas de un determinado contenido. Según von Wright, la "competencia normativa" se refiere al poder que deriva de una norma para actuar como autoridad normativa. Este autor considera que las normas de competencia pueden actuar junto con otras normas de obligación y combinarse con ellas. En dichos casos la auto-

61 Bulygin, "Sobre las normas de competencia”, cit., p. 488. 
ridad no está facultada para decidir si ha de emitir la norma, sino solamente para determinar su contenido. ${ }^{62}$

Siguiendo a von Wright es posible distinguir entre dos especies de permiso, ${ }^{63}$ si se considera que un acto está permitido simplemente por el hecho de que no esté prohibido, se puede hablar de un permiso débil. El permiso fuerte, en cambio, procede de una prescripción positiva, por lo que está sometido a una norma y no está prohibido. Esto presupone que la autoridad ha considerado su status normativo y decide permitirlo. La diferencia radica en que el permiso débil no está prohibido, pero no se encuentra sometido a una norma, por lo que no constituye un carácter independiente de las normas. En consecuencia, es su opinión que no es una norma o prescripción en sentido estricto.

Para von Wright es posible distinguir al menos dos tipos de permiso fuerte: el acto es permitido, por lo que a la autoridad no le interesa si el sujeto lo realiza o no $\left(\mathrm{P} p_{\wedge} \mathrm{P} \neg \mathrm{p}\right)$. La calificación del status normativo se puede entender en su opinión como tolerancia, aun si se trata de un permiso fuerte. ${ }^{64} \mathrm{O}$ bien como el acto que se encuentra permitido y se combina con una prohibición de obstaculizar o impedir al titular del permiso de hacer dicha cosa (este es el sentido por ejemplo de las libertades y derechos fundamentales, df $\mathrm{Pp}=\mathrm{Pp} \wedge \mathrm{F} \neg \mathrm{Pp})$. En dicho caso, el sujeto normativo tiene un derecho frente a los sujetos de la prohibición.

La noción más fuerte de permiso en von Wright implica hacer un acto posible, esto lo llama habilitar a alguien para algo. Si un permiso de hacer alguna cosa se combina con un mandato de habilitar al titular del permiso de la cosa permitida, entonces según von Wright el sujeto de la norma permisiva tiene una acción frente a los sujetos del man-

62 Norma y acción, cit., pp. 195 y ss. A esta misma conclusión llegan Alchourrón y Bulygin en Introducción a la..., cit.

63 Para Opalek y Wolenski, esta distinción como la presentan a su vez Alchourrón y Bulygin es superficial y puede producir complicaciones. J., "On weak and strong permissions once more" en Rechtstheorie, Alemania, núm. 17, 1986, p. 83.

64 Von Wright, cit., pp. 103-107. 
dato de habilitar. ${ }^{65}$ Se trata de una norma de permisión que se vincula a otra que obliga a un tercero (puede ser un particular o una autoridad) hacer posible la realización de la acción. Este tipo de permiso no presenta una modalidad deóntica compleja, pues se trata de la conjunción de dos normas distintas, lo que se puede decir que haría del permiso fuerte, un permiso "reforzado".

La teoría de las normas o lógica deóntica de G. H. von Wright en Norma y acción es esencialmente una teoría de los núcleos normativos, esto es, del carácter, el contenido y la condición de aplicación que son los elementos que lo integran. En su opinión el núcleo normativo es una parte de la estructura lógica que las prescripciones tienen en común con otros tipos de normas. ${ }^{66}$ En relación con el análisis de las normas jurídicas, von Wright, refiriéndose a las normas que son prescripciones, distingue seis componentes: el carácter, el contenido, la condición de aplicación, la autoridad, el sujeto y la ocasión. Los últimos tres son característicos de las normas jurídicas, según von Wright. Además, señala otros dos elementos propios de las normas jurídicas que, sin embargo, no son componentes de las prescripciones en sentido estricto, que son la promulgación y la sanción. 67

En su opinión, la teoría de los núcleos normativos es inadecuada para analizar normas de orden superior, tales como las normas de competencia. Considero útil, sin embargo, el análisis de los elementos de la norma jurídica, aun cuando solamente sean evaluados de manera indicativa a partir de la propuesta de von Wright. Sobre todo porque para la determinación de la naturaleza de las normas de competencia es relevante identificar al sujeto normativo y la autoridad, así como averiguar si tienen un contenido específico.

65 Ibidem, p. 104.

66 Ibidem, p. 87.

67 Ibidem, p. 88. 
En función del carácter de la norma, von Wright clasifica a las prescripciones de la siguiente manera: "Si una prescripción se da para que algo deba ser hecho, a menudo la llamamos mandamiento $u$ orden. Si se da para que algo pueda ser hecho, la llamamos permiso. Si, finalmente se da para que algo deba ser hecho, le llamamos prohibición". ${ }^{6}$ El "carácter" de la norma depende de si la norma se emite para que algo deba o pueda o tenga que ser o no ser realizado.

Para representar el carácter de "deber" de las normas introduce el símbolo $\mathrm{O}$, y para el carácter de "poder" utiliza el símbolo P. Las normas con carácter de "deber" pueden también ser llamadas "normas obligación" y la normas con carácter de "poder", "normas permisivas". Es por ello que puede hablar del "carácter -O" o del "carácter -P" de las normas, así como de "normas -O" y "normas -P". 69 Con lo cual parece ofrecer solamente dos opciones para las normas de competencia, pues o bien son obligatorias o son permisivas. De tal forma, las normas de competencia solamente pueden ser o normas que establecen un deber, ya sea una obligación o prohibición, o bien permisivas, puesto que von Wright no considera otra opción ni modalidades complejas. Dicho autor opta por el carácter permisivo aun en los casos en que las normas de competencia sean de ejercicio debido.

Con el "contenido" de una norma se refiere aquello que debe o puede o tiene que hacerse o no hacerse; las normas positivas refieren actos y las negativas, abstenciones. En consecuencia, el contenido de una prescripción es en particular la acción prescrita, ya sea mandada, permitida o prohibida. ${ }^{70}$ Von Wright señala que el contenido de una norma puede ser mixto, esto es, regular actos y abstenciones, un compuesto que se podría llamar mandato-prohibi- 
ción. ${ }^{71}$ En el caso de las normas de competencia el contenido es un acto normativo, ya sea para emitir o modificar una norma, o para eliminarla parcial o totalmente.

El concepto de "condición" de aplicación en Norma y acción, se refiere a las condiciones de ejecución de los actos, o en palabras de von Wright, a "aquella condición que tiene que darse para que exista oportunidad de hacer aquello que es el contenido de una norma dada". ${ }^{72}$ Con ello se refiere a las condiciones de ejecución de los actos elementales correspondientes. Von Wright distingue a las normas en categóricas e hipotéticas, en el caso de las primeras la condición se encuentra en el propio supuesto de la norma, esto es, está dada por el contenido de la norma y no se requiere ninguna otra condición. En el caso de las segundas se prevé una condición adicional, normalmente en su formulación. ${ }^{73}$ En las normas de competencia, ésta es tácita: ejercer la competencia en casos oportunos o necesarios (si se presenta un caso al tribunal debe el juez emitir una resolución, por ejemplo). Por lo que se puede considerar que la condición de aplicación de las normas de competencia es hipotética y puede estar prevista en otra norma, ya que requiere la pertenencia al sistema jurídico de una norma superior que atribuye la competencia, pero además es la situación que debe presentarse como oportunidad para emitir o aplicar una norma o abstenerse de hacerlo. Así corresponde evaluar si la competencia debe ser ejercida cada vez que se presenta la condición de aplicación de la norma que regula un acto normativo, o si la autoridad puede optar libremente entre emitirlo o no.

En el caso de las normas de competencia resulta relevante revisar los otros tres elementos que no forman parte del núcleo normativo, puesto que constituyen caracteristicas específicas de las normas jurídicas. Por "autoridad" de

71 Cabría preguntarse si no implica una contradicción ordenar la realización y la omisión de la misma conducta, a menos que se regulara en sentido permisivo.

72 Von Wright, cit., p. 90.

73 Ibidem, p. 91. 
una prescripción, von Wright entiende al agente que emite la prescripción. La autoridad ordena, permite o prohíbe a determinados sujetos hacer determinadas cosas en determinadas ocasiones. Se refiere a la "autoridad normativa" competente para atribuir o delegar competencia, ya sea de manera total o parcial. Este tipo de normas solamente pueden ser emitidas por cierto tipo de sujetos, definidos por su propia competencia como autoridad en sentido estricto.

Por último, el "sujeto" de una prescripción es el agente a quien se dirige, a quien se puede considerar como el sujeto normativo. La autoridad obliga, permite o prohíbe a los sujetos hacer o abstenerse de la realización de ciertas acciones. ${ }^{74}$ En el caso de las normas de competencia, el sujeto siempre es un agente con carácter de autoridad, investido de una función que le permita crear o modificar normas jurídicas. ${ }^{75}$

La "ocasión" se refiere a esa parte del enunciado normativo en que se establece el lugar y tiempo en que la conducta prescrita debe realizarse. De conformidad con la clasificación hecha por von Wright, las normas que se refieren a una ocasión específica son consideradas como particulares con relación a la ocasión, al igual que aquellas que sean para un número finito de ocasiones. Si las normas de competencia son entendidas como normas de conducta entonces son generales, puesto que parecen ser emitidas para un número ilimitado de ocasiones.

La "promulgación" está relacionada con el acto de creación de las normas jurídicas, denominada por von Wright como acción normativa, y se refiere al acto de emisión de una prescripción. 76 Según von Wright, la "formulación" son las palabras usadas al enunciar la norma, por lo que señala que las prescripciones dependen del lenguaje. En consecuencia, la promulgación puede ser entendida como

74 Ibidem, p. 93.

75 Ibidem, pp. 93-95.

76 Ibidem, pp. 131 y 139. 
la formulación lingüística de una norma prescriptiva. ${ }^{77} \mathrm{La}$ promulgación permite a los sujetos normativos conocer la norma, pero no es condición suficiente - según él- para completar la acción normativa. ${ }^{78}$ Es por ello que la autoridad, al promulgar una norma, le añade la sanción para dar efectividad a su voluntad. ${ }^{79}$ La definición de "sanción" es de carácter punitivo para von Wright, ya que la concibe como "amenaza de castigo, explicito o implicito, por desobediencia de la norma". Para él, la función de la sanción es motivar la obediencia. ${ }^{80}$

\section{SOBRE EL CARÁCTER DEÓNTICO DE LAS NORMAS DE COMPETENCIA}

Si las normas de competencia constituyen un permiso o una obligación es una pregunta a la que el debate sobre las normas de competencia no ha podido dar una respuesta genéricamente aceptada. Por otra parte, la discusión sobre la estructura lógica de las normas ha conducido a un más severo cuestionamiento sobre la relevancia práctica de la lógica deóntica. De manera que aún queda por descubrir si la noción de atribución, poder o facultad constituye una modalidad deóntica especial y autónoma, que de ser así debe ser distinguida de las modalidades de obligación y permisión, o si en cambio se trata tan sólo de una o de la otra, o tal vez, de una conjunción funcional.

Se puede decir que las normas de competencia son, en general, enunciados de deber ser (Sollsätze) que establecen que una conducta es obligatoria o permitida, o tal vez ambas. Para resolver esa cuestión, las normas deben ser analizadas lógicamente, y las modalidades deónticas diferenciadas para poder identificar el carácter de las normas de competencia. Para el análisis y determinación de la cuali-

77 Ibidem, 109 y 110.

78 Ibidem, p. 139.

79 Ibidem, p. 27.

80 Ibidem, p. 139. 
dad de norma son considerados los siguientes operadores, los cuales considero como autónomos: el operador de obligación $-\mathrm{O}$, el operador de prohibición $-\mathrm{F}$, y el operador de permisión -P. La determinación del carácter deóntico de las normas de competencia es un prerrequisito del análisis de su naturaleza. En mi opinión, los enunciados normativos sobre la competencia requieren de consideraciones especiales, ya que no parecen responder a una sola modalidad autónoma, sino que se integran por una compleja. ${ }^{81}$

En Introducción... Alchourrón y Bulygin señalan que un enunciado deóntico o de deber, es "toda expresión formada por un operador (carácter deóntico), seguida por un contenido deóntico y también a todo compuesto proposicional de tales expresiones". Ellos consideran cuatro operadores modales deónticos: $\mathrm{P}$ (permitido), $\mathrm{O}$ (obligatorio), $\mathrm{Ph}$ (prohibido) y $F$ (facultativo). Este último se refiere al caso en que la realización de una conducta y su omisión están permitidas $(\mathrm{Pp} \wedge \mathrm{P} \neg \mathrm{p})$, por lo que la permisión, en su carácter de operador primitivo, no prevé la posibilidad de la omisión de la acción $(\mathrm{Pp}=$ df $\mathrm{Pp} \wedge \neg \mathrm{P} \neg \mathrm{p})$. El término "facultativo" utilizado por estos autores para este carácter normativo o deóntico, no se refiere a una potestad, sino a la permisión indiferente de von Wright, en virtud de las posibles interpretaciones de la permisión. ${ }^{82}$ La conjunción de la permisión de una acción $(\mathrm{Pp})$ y de su omisión $(\mathrm{P} \neg \mathrm{p})$ es la posición libre o facultativa que permite las alternativas de realizar o no la conducta a elección del sujeto normativo, $y$ que ha sido simbolizada como Lp por Alexy. ${ }^{83}$ Esta es la permisión en sentido de libertad: $\mathrm{Lp}={ }_{\mathrm{df}} \mathrm{Pp} \wedge \mathrm{P} \neg \mathrm{p}$, la cual es equivalente a la permisión explícita $(P A)$ de Holländer como se menciona a continuación.

81 Como hace Sieckmann, por ejemplo. En Regelmodelle und Prinzipienmodelle des Rechtssystems, Baden-Baden, Nomos Verlagsgesellschaft, 1990.

82 Introducción a la metodología de las ciencias jurídicas y sociales, cit., pp. 36 y 74.

83 Alexy, Robert, Teoría de los derechos fundamentales, Madrid, Centro de Estudios Constitucionales, 1993, p. 185. 
En relación con los diversos tipos de permisión, Holländer sugiere que existen 3 tipos básicos de permisión: ${ }^{4}$ 1. La implícita $(P G)$, que se deduce de una obligación y se puede expresar como "debo, entonces puedo" (de modo que su ejercicio es obligatorio); 2 . La explícita $(P A), 85$ que significa que en los casos en que una determinada conducta (p) esté permitida, entonces también la negación de dicha conducta $(\neg \mathrm{p})$ está permitida (por lo que su ejercicio es potestativo), y 3. La indiferente (PI) que se infiere de la ausencia de regulación. Por lo tanto, una conducta y su negación están permitidas cuando no han sido reguladas (en consecuencia su ejercicio no es jurídicamente relevante).

Como se puede observar la permisión puede ser entendida de distintas formas, ${ }^{86}$ no obstante, la permisión indiferente $(P I)$ no puede ser considerada como jurídica ya que no está prevista en una norma. Es por ello que en ocasiones se habla de una "permisión débil", 87 la cual deriva de una ausencia de prohibición. La permisión implícita $(P G)$, al estar asociada con una conducta obligatoria, no solamente debe sino que tiene que poder ser realizada. Este "poder" no se refiere solamente a una cuestión de orden fáctico, de posibilidad lógica, sino a que la conducta "debe poder" realizar-

84 Holländer, Rechtsnorm, Logik und Wahrheitswerte, Baden-Baden, Nomos Verlagsgessellschaft, 1993, pp. 87-88; y en Holländer y Knapp, "Zur Problematik des deontischen Quadrats in der deontischen Logik", ARSP, vol. 77, Stuttgart, 1991, t. 3, pp. 402 y 403. Weinberger hace una definición similar de los tipos de permisión en Norm und Institution, Viena, Mansche Verlags- und Universitätsbuchhandlung, 1988, p. 68.

85 Es equivalente a la permisión designada como Lp por Alexy, Teoría de los derechos fundamentales, cit., nota 83, p. 200. Weinberger denomina "indiferencia" al caso en que esté permitido realizar y no realizar una conducta. Él utiliza la letra "P" para simbolizar el permiso y define la indiferencia como: $\mathrm{Ip} \longrightarrow \mathrm{Pp} \wedge \mathrm{P}_{\neg p}$, en Norm und Institution, cit., 1988, p. 62.

86 Para Weinberger existen también diversos conceptos de permiso; su propuesta coincide con la de Holländer a pesar de utilizar una simbología diferente. Cf. ibidem, p. 68.

87 Alchourrón y Bulygin realizan un análisis extenso sobre el significado de la permisión y sus implicaciones en las relaciones entre normas y revisan las posiciones de von Wright y Weinberger respecto de las permisiones débiles y fuertes, en "Permission and Permissive Norms", Theorie der Normen, Festgabe für Ota Weinberger zum 65. Geburtstag, en Krawietz, W. et al (eds.), Berlin, Duncker und Humblot, 1984, pp. 349-371. 
se efectivamente, por lo que no debe ser impedida su realización ni sus consecuencias. Esto significa, por una parte, que la conducta obligada no debe ser prohibida, y por la otra, que no existe una libertad para decidir sobre la realización de la conducta. En cambio, la permisión explícita $(P A)$ se encuentra expresamente prevista en una norma; y por ello algunos autores la denominan "permisión fuerte". Un permiso de este tipo establece la posibilidad de realizar o no la conducta prescrita, ya que subsiste la libertad de utilizar el permiso (o no hacerlo) a elección del individuo.

Tomando en cuenta estas tres opciones, si se pretende considerar a las normas de competencia como permiso, la regulación de una permisión tiene normalmente el significado de $P A$, porque de ninguna forma puede inferirse de su ausencia de regulación, como en PI. Afirmar que las normas de competencia son normas permisivas (s.s.) implica sostener que su ejercicio es esencialmente optativo. Sin embargo, el ejercicio de una competencia no es potestativo, es más, puede estar vinculado con una obligación. De modo que si se interpretan como PG derivan de la obligación de ejercer la competencia, por lo que su ejercicio seria obligatorio, pero la competencia solamente se ejercita al presentarse las circunstancias respectivas, es condicional. En consecuencia, ninguno de estos tipos de permiso permite explicar de manera satisfactoria las normas de competencia, porque como facultad puede vincularse o derivarse de la obligación de su ejercicio, pero no siempre es obligatorio el ejercicio, ya que depende de ciertas condiciones.

En el otro extremo se encuentra Kelsen, para quien facultar implica ordenar, por lo que la competencia entendida en sentido estricto, no puede ser concebida como un permiso; y aun cuando en su opinión constituyen funciones distintas de la norma, facultar puede implicar obligar. ${ }^{88}$ Ross, a su vez considera que las normas de competencia son lógicamente reducibles a normas de conducta puesto que hacen obligatorio actuar de conformidad con normas de conducta

88 Kelsen, Allgemeine Theorie der Normen, cit., p. 83. 
que han sido creadas conforme al procedimiento previsto en ellas. 89

El problema de la concepción de las normas de competencia como una modalidad compleja que se integra por una obligación y una permisión, se manifiesta en el hecho de que estas modalidades no siempre son compatibles. Su compatibilidad depende no solamente de la interpretación de la permisión, sino también del rango de la norma en un sistema organizado jerárquicamente. De modo que debe determinarse primero la naturaleza y cualidad de las normas de competencia, antes de poder determinar su carácter.

\section{CONCLUSIONES}

En el sistema jurídico coexisten distintos tipos de normas, entre las cuales las normas de competencia juegan un rol primordial en la identificación y fundamentación del mismo. Considero que las normas de competencia constituyen un tipo especial de normas jurídicas, que no solamente regulan el sistema jurídico, sino también un tipo determinado de conducta que debe ser realizado. Como consecuencia de su importancia, las normas de competencia deben ser reguladas de manera clara y precisa, no solamente por lo que a su ejercicio se refiere, sino también respecto a sus consecuencias.

Si se conciben a las normas de competencia como normas permisivas, son entonces reglas de conducta distintas de la norma que obliga a un juez a juzgar. En consecuencia, esta obligación opera de manera conjunta con la norma de competencia que faculta al juez de la siguiente manera: $\mathrm{Op} \wedge \mathrm{Pp}$, o a la inversa dado que la competencia debe preexistir para poder cumplir con el deber de juzgar, así: $\mathrm{Pp} \wedge \mathrm{Op}$. Aunque parece más bien, que se establece una relación de consecuencia como sigue: $\mathrm{Pp} \rightarrow \mathrm{Op}$. En estos casos resultaria interesante realizar el análisis lógico de las

89 Ross, Directives and Norms, cit., p. 118. 
consecuencias de cada una de estas interpretaciones. Sobre todo porque la inversa, independientemente de las cuestiones relativas al teorema de lógica deóntica (si una conducta es obligatoria debe estar permitida), no es válida, $\mathrm{Op} \rightarrow \mathrm{Pp}$, pues haría innecesaria la norma facultativa $\mathrm{y}$, por ende, afirmaría el carácter obligatorio de las normas de competencia.

En estos casos se puede decir que una norma categórica, en el sentido de von Wright, se transforma en una norma hipotética, porque se suma otra condición de aplicación. También se pueden entender como dos normas jurídicas que operan de manera conjunta. Pero, ¿qué ocurre entonces en los casos en que no existe una obligación de ejercer la competencia? Si el carácter de las normas de competencia es la permisión, entonces su ejercicio se deja al arbitrio del funcionario público aun cuando el supuesto se produzca. ¿De dónde derivaría entonces la responsabilidad, la facultad de sanción o la posibilidad de exigir su realización?

Parece que la modalidad deóntica de las normas de competencia no es autónoma, estas normas operan de conformidad con lo previsto al respecto por otras normas del sistema jurídico, por lo que en esa medida constituyen normas dependientes de otras, o prevén modalidades complejas. Las normas de competencia no son simplemente permisos ni obligaciones, pues operan mediante la conjunción de ambos caracteres.

$\mathrm{Si}$ en el sistema jurídico existe una norma de competencia para emitir una norma jurídica o realizar un acto, y se da la ocasión, la competencia debe ser ejercida, por lo que no puede ser considerada una permisión en el sentido de Lp, sino como una modalidad compleja que se integra por la facultad de actuar $\left(\mathrm{Pp}_{\wedge} \neg \mathrm{P}_{\neg \mathrm{p}}\right)$ y el deber de ejercer la competencia, lo cual le confiere un carácter predominantemente obligatorio. 